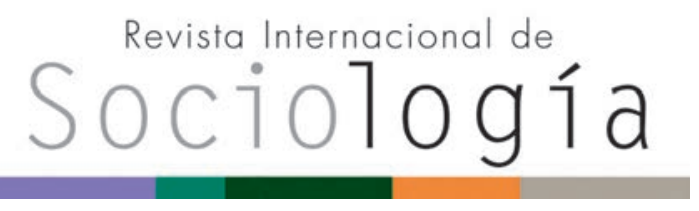

Revista Internacional de Sociología RIS

vol. 77 (1), e121, enero-marzo, 2019, ISSN-L:0034-9712

https://doi.org/10.3989/ris.2019.77.1.17.153

\section{EL CASO DE GANEMOS ZARAGOZA: UNA APROXIMACIÓN DESDE LA SOCIOLOGÍA RELACIONAL}

Jaime Minguijón Pablo

Universidad de Zaragoza

ORCID iD: https://orcid.org/0000-0002-8702-0156

jmingui@unizar.es

DAVID PAC SALAS

Universidad de Zaragoza

ORCID iD: https://orcid.org/0000-0001-9729-7688

davidpac@unizar.es

Cómo citar este artículo / Citation: J. Minguijón Pablo, J. y D. Pac Salas. 2019. "El caso de Ganemos Zaragoza: una aproximación desde la sociología relacional”. Revista Internacional de Sociología 77(1):e121. https://doi.org/10.3989/ris.2019.77.1.17.153

\begin{abstract}
Resumen
En este artículo se presentan los resultados de una investigación que ha analizado la génesis del movimiento Ganemos Zaragoza/Zaragoza en Común (GZ/ZeC) y el paso a su constitución como formación política. A partir del análisis de los datos de una encuesta $(n=253)$ y entrevistas a informantes clave, mostramos que los movimientos sociales (entendidos como una nueva red social) nacen en situaciones sociales "enredadas".

Para alcanzar tal fin, nos situamos en la mirada teórica de los movimientos sociales desde una perspectiva relacional. Entre sus principales resultados se ha podido comprobar cómo $\mathrm{GZ} / \mathrm{ZeC}$ se tejió, en un primer momento, a través de los contactos y alianzas que se establecieron entre movimientos sociales preexistentes, que terminaron por construir la malla relacional desde la que se fue edificando y fortaleciendo el movimiento. Por tanto, este texto sirve para comprender el proceso de configuración de las candidaturas de confluencias municipales en las elecciones de mayo de 2015.
\end{abstract}

Palabras Clave

Confluencias municipales; Movimiento social; Partidos políticos; Redes sociales; Relación social.

\section{THE CASE OF GANEMOS \\ ZARAGOZA: AN APPROACH FROM RELATIONAL SOCIOLOGY}

Copyright: @ 2019 CSIC. Este es un artículo de acceso abierto distribuido bajo los términos de la licencia de uso y distribución Creative Commons Reconocimiento 4.0 Internacional (CC BY 4.0).

Recibido: 31/10/2017. Aceptado: 01/06/2018

\section{Abstract}

This article presents the results of research related to analyzing the genesis of the Ganemos Zaragoza / Zaragoza in Common (GZ/ZeC) movement and its passage to constituting a political formation. Through an analysis of a survey data $(n=253)$ and key informant interviews, we show that social movements (understood as a new social network) are born in "convoluted" social situations.

To achieve this goal, we look at the theoretical view of social movements from a relational perspective. Among the main results we can see how $G Z / Z e C$ was formed, at first, through contacts and partnerships established between preexisting social movements, that eventually ended up gaining relational support from which the movement was built and strengthened. Therefore, this text serves to understand how the process was set up for candidates in the municipal elections of May 2015.

\section{KeYWORDS}

Municipal confluences; Political parties; Social movement; Social networks; Social relation. 


\section{INTRODUCCIÓN}

En el último lustro hemos asistido en España a la aparición de nuevos movimientos reivindicativos (las mareas, las marchas por la dignidad, Stop Desahucios, etc.), a la creación de un nuevo partido político de ámbito nacional (Podemos) que ha terminado alcanzando una significativa representación en diferentes niveles institucionales $y$, finalmente, a la emergencia de un sinfín de iniciativas de ámbito municipal (las llamadas confluencias) que, en algunos casos, han llegado a alcanzar el gobierno de capitales importantes (siendo las más relevantes Madrid, Barcelona y Zaragoza).

El presente artículo, centrándose en el análisis en profundidad del proceso de génesis de una de estas candidaturas municipalistas (Zaragoza en Común), pretende realizar una aportación al debate en torno a los procesos de formación de nuevas formaciones políticas desde la perspectiva específica del papel que, en ese proceso, juegan los movimientos sociales.

Desde la ciencia política, las explicaciones sobre el nacimiento de un nuevo partido político han girado en torno a cuatro líneas argumentativas básicas: las que encuentran su génesis en el propio desarrollo de las instituciones legislativas (Duverger 1980), las teorías de las crisis históricas (ligadas al nacionalismo y a las crisis de legitimidad) y las teorías desarrollistas, ligadas a procesos de modernización (o revolucionarios) de los países (Charlot 1971), además de los impulsados por líderes carismáticos. Desde la sociología y, específicamente, desde los analistas de los movimientos sociales, el enfoque que nos interesa es aquel que analiza los impactos de los movimientos sociales en el ámbito político (en la línea de los análisis de Giugni, Bosi y Uba 2016; Amenta 2014; Amenta y Caren 2013; Porta y Diani 2011; Johnston 2011, por citar solo algunos de los más significativos de la última década), uno de los cuales es la generación de una nueva formación política. Estos últimos enfoques entroncan con aproximaciones más amplias que profundizan en el impacto de los movimientos en la superestructura, ya sea esta política (Touraine 1990: 117 y s.) o cultural (Melucci 1994).

Este variado enmarque teórico ha servido a diferentes autores para ofrecer una pluralidad de explicaciones en torno al nacimiento de las confluencias, aportaciones que serán revisadas de forma crítica identificando las limitaciones que presentan. Por otra parte, este primer análisis servirá para comprobar cómo, para la mayoría de estos autores, el 15M es identificado como un antecedente sin el cual no pueden llegar a entenderse las confluencias ni los movimientos sociales previos que las impulsaron.

Una vez realizada la revisión crítica de las explicaciones sobre el nacimiento de las confluencias, presentaremos la sociología relacional como la mejor aproximación teórica para dar una respuesta adecuada a esta cuestión. Trataremos de demostrar que, para analizar las confluencias como un nuevo movimiento social que ha derivado en una formación política, la perspectiva relacional nos permite analizar su contínuum temporal, haciendo comprensible el itinerario seguido a través de una serie de procesos y mecanismos sociales que serán descritos pormenorizadamente.

$Y$, finalmente, aplicaremos esta perspectiva a un estudio de caso: la génesis de GZ/ZeC. En este momento, el objetivo se centrará en profundizar en los mecanismos explicativos causales, trascendiendo la mera puesta de relieve de las redes sociales, respondiendo a la que de hecho es la principal pregunta de investigación (¿cómo se configuran las redes que explican la aparición y configuración de GZ/ZeC?), ofreciendo una explicación sociológica que vaya más allá de la sucesión de los acontecimientos.

\section{LAS CONFLUENCIAS MUNICIPALISTAS: INTEN- TOS EXPLICATIVOS}

La década de los ochenta del siglo pasado inició en el mundo una ola de reformas neoliberales que pueden considerarse como el punto de partida de un nuevo ciclo de protestas reactivas, abierto en Europa en la década de los noventa por los movimientos antiglobalización y anti-Maastrich (Calle 2015) y que tuvo su punto cumbre en la oleada de protestas que recorrieron el mundo a partir de la crisis del capitalismo global de 2008, extendiéndose desde Túnez a Estados Unidos, desde Turquía a Brasil, desde Grecia a Portugal y España (Gerbaudo 2012; Castells 2012; Romanos 2016). En el caso de España, el punto álgido de este proceso contestatario se dio con el llamado movimiento $15 \mathrm{M}$, ya ampliamente analizado desde múltiples perspectivas por los estudiosos de los movimientos sociales (Monge 2017).

Transcurridos tres años desde el 15M, a mediados del 2014, una vez celebradas las elecciones europeas y con la perspectiva de las elecciones municipales de mayo de 2015, España se encontraba en un nuevo escenario social y político, cuyos cambios más significativos fueron los siguientes:

- En una primera fase, la disminución del apoyo a los grandes partidos (PP y PSOE) y el incremento del apoyo a los pequeños (Anduiza, Martín y Mateos 2013; Casanueva 2014).

- La revitalización, reorientación y transformación de los movimientos sociales preexistentes (por ejemplo, la Plataforma de Afectados por la Hipoteca (PAH), que generó el movimiento Stop Desahucios), así como la emergencia de otros nuevos (las mareas, las marchas por la dignidad, Rodea el Congreso, etc.), con un papel muy activo en las protestas contra los recortes originados por la crisis (Subirats 2015a; Martínez y Domingo 2014). 
- El surgimiento de un movimiento de carácter políticono partidista que promovía una transformación desde lo local del sistema constitucional (Movimiento por la Democracia, Municipalia), y que se había nutrido de los marcos referenciales (asamblearismo, participación, etc.) del 15M (Aguiló y Sabariego 2016; Romanos y Sádaba 2016).

- La emergencia de nuevos partidos políticos (Podemos) y la ampliación de la escala territorial de otros (Ciudadanos), que terminaron por difuminar el tradicional bipartidismo en España (Subirats 2015a; Porta 2015; Hoz 2015; Navarro 2014).

En este escenario, y ante el éxito inesperado de Podemos en las elecciones europeas, diferentes movimientos sociales, así como partidos políticos de la izquierda del arco ideológico (nuevos, como Podemos, y tradicionales, como Izquierda Unida y Equo) plantearon en el verano de 2014 la necesidad de generar plataformas de diversa índole para presentarse a las elecciones municipales de 2015. La primera plataforma en crearse fue Guanyem Barcelona, en julio de 2014, al frente de la cual se situó Ada Colau, carismática y mediática portavoz de la $\mathrm{PAH}$ hasta ese momento, con un largo historial de activismo en otras organizaciones y movimientos sociales (Romanos y Sádaba 2016). Tras Barcelona, diversas plataformas proliferaron por todo el país, entre las que destacaban Ganemos Madrid y Ganemos Zaragoza.

Desde el verano de 2014 hasta la celebración de las elecciones municipales, por cuestiones legales, los Ilamados "Ganemos" derivaron en diversas marcas electorales, como Barcelona en Comú, Ahora Madrid y Zaragoza en Común. En esas tres capitales las candidaturas municipalistas de confluencia terminaron alcanzando el gobierno de sus respectivos ayuntamientos.

En las explicaciones aportadas hasta el momento sobre el nacimiento de las convergencias municipalistas, encontramos dos elementos compartidos. De una parte, el análisis del contexto económico (crisis) y político (corrupción y crisis de legitimidad del modelo representativo), aspecto muy bien desarrollado por Rodon y Hierro (2016). De otro lado, el situar al $15 \mathrm{M}$ como origen de las mismas, ya sea como una causa directa o mediata. En este sentido, el impacto del $15 \mathrm{M}$ es visto desde dos perspectivas:

- Desde una visión más social, el 15M dio lugar a un proceso de revitalización, reordenación y transformación del tejido social (Subirats 2015a; Martínez y Domingo 2014), generándose nuevos movimientos, como las mareas (Díaz-Parra y Jover-Báez 2016), que terminaron configurando un nuevo "ecosistema" de experimentos sociopolíticos (Subirats 2015b).

- Desde una visión más política, el 15M fue un cultivo que permitió la activación política de los jóvenes (Cruz 2014), lo que favoreció la emergencia de un nuevo partido político (Podemos), que contribuyó a la configuración de las confluencias municipalistas (Fernández-Llebrez 2015; Martín 2015).

Pero más allá del 15M, buscando las causas inmediatas, encontramos diferentes hilos explicativos, atendiendo a los autores consultados:

Un primer grupo de autores describe un contínuum entre el $15 \mathrm{M}$, la emergencia de nuevas formas de expresión colectiva del descontento ante la crisis y su institucionalización, primero en la fórmula "Podemos" y, posteriormente, con las confluencias (Díaz-Parra y Jover-Báez 2016). Sería una explicación de corte más sistémico, en la que las confluencias se entienden como una estrategia electoral de las fuerzas progresistas (Fernández-Llebrez 2015) o de determinados líderes (Romanos y Sádaba 2016). En esta línea se encuentran igualmente Cruz (2014) y Mir (2015). La limitación de esta perspectiva es que tiende a observar el fenómeno analizado como una evolución "natural" de un proceso propio de un movimiento social, sin explicar adecuadamente, a nuestro juicio, tal evolución.

Un segundo grupo de autores ponen el acento en la perspectiva relacional $y$, más concretamente, en la explicación de las confluencias como un proceso de agregación de redes sin una organización estructurada (Rodríguez 2015). Hablan de una dimensión organizativa reticular, que agrega desde lo local, acumuladora de microparticipaciones, sin centros gestores muy visibles (Romanos y Sádaba 2016), en la que determinados activistas (innovadores tecnológicos) desempeñaron un papel básico como conectores y facilitadores entre diferentes grupos, colectivos y tendencias. Para Subirats (2015b), los movimientos sociales que están en el origen de las nuevas configuraciones políticas tendieron a articularse en forma de maraña entrelazada de pequeños grupos, redes sociales y con múltiples conexiones. En esta línea Aguiló y Sabariego emplean el concepto de "confluencia en red" (2016:108).

Sin embargo, los autores que adoptan la orientación relacional no acaban de abordar con detalle y en lo concreto en qué ha consistido ese proceso reticular. Solo Subirats (2015b: 126) llega a describir cómo en muchos casos se empezaba en ámbitos sociales de micromovilización, que era donde se establecían los vínculos a partir de los cuales la gente se comprometía, generaba lazos y decidía emprender determinadas movilizaciones. Y emparenta este proceso con el concepto de "swarming" (enjambrazón), que trata de dar cuenta de la capacidad de las redes de generar coordinación en la dispersión (Subirats 2015b: 127).

Precisamente, el reto del presente artículo reside en profundizar en la génesis de las confluencias desde la perspectiva relacional, fijándonos en un estudio de caso (Ganemos Zaragoza) con el fin no solo de identificar las redes sociales que hacen posible su emer- 
gencia, sino de dar respuesta a uno de los elementos que más desdibujados queda en la obra de los teóricos de los movimientos sociales que han adoptado la perspectiva relacional: más allá de la importancia de las redes sociales en la génesis y la evolución de los movimientos sociales, queda por dilucidar "qué redes explican qué" y "bajo qué condiciones las redes concretas adquieren importancia" (Porta y Diani 2011).

\section{MARCo TEÓRICO: SOCIOLOGÍA RELACIONAL Y MOVIMIENTOS SOCIALES}

Adentrarnos en el origen de lo social de forma exhaustiva exigiría hacer un repaso a lo que las teorías sociológicas clásicas y no clásicas dicen respecto al dilema básico entre acción individual y estructura. Pero, más allá de la propuesta concreta que hace cada una de esas escuelas, en lo que todas parecen coincidir es que, al ofrecer esas respuestas, se adentran en la difícil tarea de presentar una síntesis convincente a la dicotomía y tensión existente entre las perspectivas holísticas e individualistas en el ámbito de la investigación social.

Nuestra propuesta se inspira en una de las corrientes de la sociología que ha aportado una posible salida a esta dicotomía: la Sociología Relacional: «Mi tesis es que ni la teoría sistemática (holística) ni la teoría accionística (individualista), ni las que las combinan, pueden darnos una "comprensión adecuada" del cambio social» (Donati 1993:34). Para esta corriente sociológica, «al principio fue la relación» (Donati 2011: 17), una frase que no hacía sino sintetizar las aportaciones en este sentido de una larga tradición sociológica (Crossley 2011; White 2009; Weber 2008; Tilly 1991; Emirbayer y Mische 1998; Emirbayer 1997; Simmel 1986).

Como síntesis de toda su obra (especialmente, Donati 1993:34; 2006:55), en el Manifesto for a critical realist relational sociology, Donati (2015) pone el acento en un redescubrimiento del sentido de la causalidad de lo social, que deja de observarse o como producto de la acción social o como producto de las estructuras sociales para contemplarse como un fenómeno complejo que se produce en el interior de la relación social, que es la que está dotada de poderes causales. La tesis fundamental presentada en su Manifesto es que «...la morfogénesis de la sociedad se produce a través de las relaciones sociales, las cuales son los conectores que median entre la agencia y la estructura social» (Donati 2015: 87).

Pero la relación social en sí misma y en su unicidad no tendría el poder causal que se le otorga desde la sociología relacional si no se articulase con otras relaciones sociales, produciendo (y reproduciendo) unas estructuras sociales que poseen una materialidad diferente y que pueden ser objeto del análisis sociológico: las redes sociales. En este caso, también su estudio tiene una larga tradición en el ámbito de las ciencias sociales (Wasserman and Faust 1994; Freeman 1992; Mitchell 1969) y, para algunos autores, llegan a constituir el elemento central de las sociedades actuales (Castells 2005) ${ }^{1}$, mostrándose con una trascendencia significativa en los movimientos de indignación a escala mundial: Tahir, 15M ó Wall Street (Romanos 2016).

Atendiendo a las diferentes perspectivas que abordan la definición de red social (Emirbayer and Goodwin 1994: 1417; Christakis y Fowler 2010:27; Requena 1989:139), se puede observar que todas ellas coinciden en que en la base de la constitución de las redes sociales se encuentra las relaciones sociales ("múltiples y transversales", en la terminología de Mische 2003). Y lo que permite a un conjunto de relaciones sociales formar parte de una red es el hecho de estar interconectadas, o lo que algunos autores Ilaman "encadenadas" (Bidart, Degenne y Grossetti 2011: 51), haciendo posible la transmisión de información, opiniones, bienes y servicios, etc. ${ }^{2}$. Otra de las características de las redes sociales es que, a diferencia de las relaciones que le dan vida, «...adquieren una cualidad sustancial cosificada, alejada de la dinámica real de la interacción» (Mische 2003: 262).

Esa es la base teórica que permite defender que «el mecanismo generativo que alimenta la morfogénesis social reside en la dinámica de redes de relaciones sociales» (Donati 2015: 87, subrayado nuestro).

Podemos decir que la relación social y las redes sociales han estado presentes como objeto de interés en la obra de la práctica totalidad de sociólogos clásicos, ya sea desde una perspectiva más sistémica o más individualista, y es la base de la explicación del cambio social y de la acción colectiva en autores relevantes del ámbito de los movimientos sociales (Crossley y Krinski 2015; Diani 2004; Mische 2003; Diani y McAdam 2003; Crossley 2002; Tarrow 1996; Hedström 1994; McAdam y Paulsen 1993; Klandermans y Oegema 1987; Snow, Zurcher y Ekland-Olson 1980), llegando, en el caso de Tilly (1991: 44), a identificarla como "la unidad social básica del enfoque sociológico».

La hipótesis subyacente presente en todos estos autores es que las redes sociales preexistentes son esenciales a la hora de comprender el nacimiento y futuro desarrollo de un movimiento social. Estas redes pueden tener diferentes niveles de formalización y pertenecer a distintos campos de la vida social (el político, el sindical, el de un movimiento propiamente dicho, el familiar, el laboral, el eclesial, etc.), pero en el momento del nacimiento de un nuevo movimiento se articulan de una forma diferente a como estaban relacionadas hasta entonces, para crearlo, otorgándole tanto líderes como recursos, canales de comunicación, valores, diagnósticos y propuestas, redes de confianza e institucionales o, incluso, sus nuevos adeptos (McAdam 2003: 286). Por lo tanto, en el fon- 
do, podría decirse que los movimientos sociales se construyen sobre situaciones sociales "enredadas".

La perspectiva relacional introduce una dimensión dinámica en el estudio de los movimientos sociales, que solo son comprensibles como la consecuencia de una pléyade de «interacciones informales entre una pluralidad de individuos y grupos de asociaciones, comprometidos en un conflicto político o cultural sobre la base de una identidad colectiva» (Diani 2003: 301). De la misma opinión es Nick Crossley (2002: 93), cuando defiende que los movimientos sociales surgen en torno a redes sociales preexistentes, tanto informales (o de la vida cotidiana) como las que se forman a partir de las organizaciones.

En consecuencia, desde la perspectiva que estamos analizando los movimientos sociales, una definición operativa de este concepto debe introducir este aspecto como elemento fundamental (Tarrow 1998: 33; Porta y Diani 2011: 43; Diani 2015: 10).

\section{Planteamiento y objetivos de la inves- TIGACIÓN}

Con el objetivo de dar respuesta a las cuestiones de "qué redes explican qué" y "bajo qué condiciones las redes concretas adquieren importancia", nos vamos a centrar en el estudio de caso del nacimiento de Ganemos Zaragoza (GZ). Estas cuestiones se traducen en tres preguntas de investigación, animadas por otras tantas hipótesis subyacentes:

a) ¿Qué redes preexistentes permitieron la articulación de GZ/ZeC; pregunta hecha bajo la hipótesis de que los movimientos sociales (entendidos como una nueva red social) nacen en situaciones sociales "enredadas".

b) ¿Cómo se articularon esas redes para dar vida a GZ/ZeC; pregunta hecha bajo la hipótesis de que las diferentes redes presentes en su formación interactuaron entre ellas de manera distinta, formando varios agrupamientos.

c) ¿Qué papel jugaron las redes de diferente tipo en las distintas fases del proceso, especialmente en el momento en el que se produce el desborde; pregunta hecha bajo la hipótesis de que esos conglomerados desarrollaron papeles diferentes en las distintas fases de formación del movimiento.

Para poder responder a estas preguntas, es preciso hacer operativo el marco teórico, aprovechando las aportaciones procedentes fundamentalmente de Grossetti (2009) y White (2009), autores que permiten identificar una serie de etapas en la génesis de un movimiento social, en cada una de las cuales indicen una serie de mecanismos. Para ello, de entre los diferentes elementos que intervienen en este proceso (Soule 2004; Strang and Soule 1998), se va a prestar especial atención los elementos que tienen una dimensión interna y, especialmente, a la importancia de las redes y la interacción social.

Para facilitar su comprensión, partimos del esquema propuesto en la figura 1.

Se trata de un proceso que parte de una serie de redes preexistentes que se "acoplan" (o "reencastran", en palabras de Grossetti 2009) a través de diferentes mecanismos y durante un tiempo determinado, para terminar "desacoplándose", generando esa nueva estructura organizacional que antes no existía (White 2009). Entre esas dos fases (una inicial y otra final), se encuentra una intermedia (la de desborde), que permite al movimiento captar nuevos adeptos y alcanzan una masa crítica suficiente para garantizar su visibilidad y su éxito.

En relación con la fase del acoplamiento, los líderes de determinadas organizaciones preexistentes de diversa índole inician una serie de contactos informales en los que aparece la necesidad y conveniencia de afrontar la realidad social a través de nuevas respuestas colectivas. Mische habla de este proceso e identifica cuatro tipos de lazos entre los líderes: "beber cerveza con”, "hablar de política con”, "planear eventos con", "negociar alianzas con", en los que se detecta el importante rol que la interacción comunicativa juega en ellos (Mische 2003: 267).

En esta fase son relevantes los procesos de "contagio" entre experiencias similares que se pueden estar dando en diferentes ciudades. Hedström, Sandell and Stern (2000: 153 y ss.) explican este proceso de alineación y sumatorio de redes pertenecientes a espacios diferentes (lo que en nuestro esquema hemos denominado "locus"). Recurren a la existencia de dos tipos de redes: las redes "de nivel meso", como aquellas de baja intensidad (normalmente formadas por lo que ellos denominan "agitadores"), que ponen en conexión bordes de redes de alta intensidad, que difícilmente llegarían a conectarse sin su presencia. La red meso estaría ubicada en una dimensión macro, mientras que las redes locales serían más propias de la dimensión micro (Hedström 1994).

Siguiendo el hilo temporal, lo importante es resaltar que en la génesis de un nuevo movimiento social llega un momento en el que, más allá de los contactos informales iniciales, cuando esos líderes y activistas ya han tejido ese núcleo comunicativo e identitario básico y compartido, las organizaciones y redes preexistentes a las que pertenecen empiezan a negociar su presencia en ese nuevo espacio naciente. Se trata de procesos de negociación en los que se comparten los diagnósticos previos, se afianzan las identidades y se ponen recursos y personas en pos de la materialización de ese nuevo movimiento (Mische 2003: 262), haciéndose realidad la posibilidad comentada por Mario Diani: «los vínculos establecidos en una determinada fase pueden facilitar nuevos cambios en un contexto diferente» (Diani 1998: 247). 
Figura 1.

Lógicas generadoras de un movimiento social

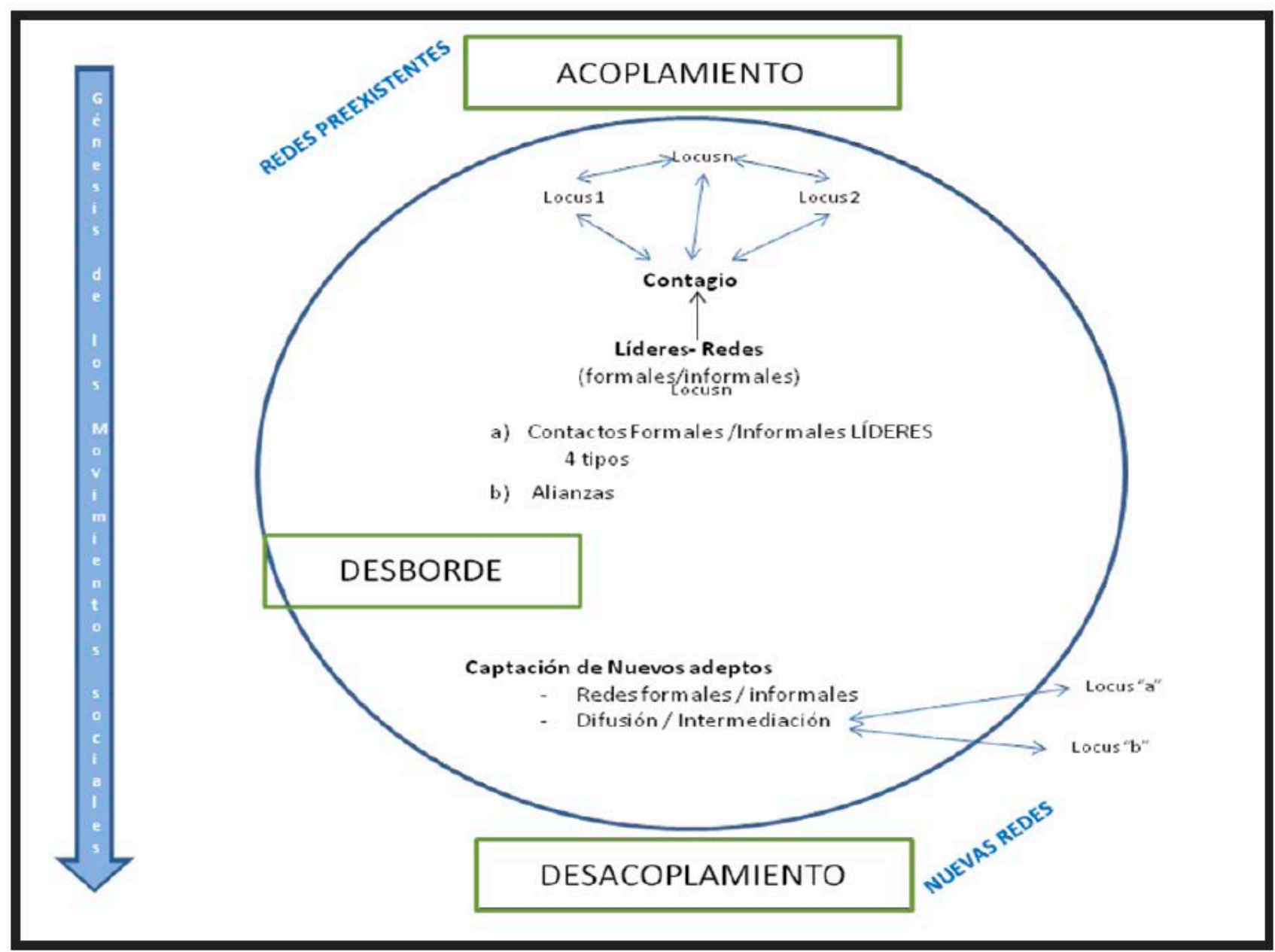

Fuente: Elaboración propia, a partir de Grossetti (2009) y White (2009).

Dando un paso más en su consolidación, el movimiento naciente se va nutriendo de nuevos miembros, perteneciesen o no a las redes preexistentes que le dieron origen. Es aquí donde se ponen las bases para los mecanismos de "desbordamiento" (Meyer and Whittier 1994), que dan paso al "cambio de escala" que describen McAdam, Tarrow and Tilly (2001: cap. 10). En este caso, paulatinamente, las redes organizacionales van perdiendo relevancia y la van adquiriendo las redes menos formales (principalmente: familiares, de amigos y laborales).

Lo interesante de este proceso es que estas redes menos formales, que normalmente duermen ajenas a lo que sucede en el exterior, especialmente en el ámbito de lo sociopolítico, en determinadas situaciones se hacen presentes en la historia social. Es algo sobre lo que ya nos advirtió Tarrow: «...los movimientos sociales tienen sus raíces en redes sociales preexistentes, depositarias de relaciones de confianza, reciprocidad y aprendizaje cultural» Tarrow (1995: 13).

A este conjunto de relaciones impersonales, en cierto sentido espontáneas (Toch 1965), en las que se apoyan los movimientos sociales para desbordar y salir a la luz pública, Enrique Laraña, siguiendo a Melucci (1994), las denomina "redes sumergidas" (Laraña 1999: 196 y ss.). Su carácter sumergido viene dado porque, aunque pueden ser esenciales en la vida cotidiana de las personas, no tienen visibilidad pública. Además, tienen la doble capacidad de gestar nuevas estructuras de sentido que pueden llegar a alcanzar la categoría de "alternativas" respecto a las que predominan en la sociedad e insuflarlas en los movimientos sociales, así como del proceso inverso, es decir, de transmitir los efectos, expectativas y resultados de los movimientos sociales a las personas. Los mecanismos a través de los cuales se van extendiendo esos sentimientos compartidos al interior de la red son variados, pero destacan los de "imitación" y "persuasión" (Hedström, Sandell and Stern 2000: 150-152).

Estos vínculos o lazos pueden pertenecer a la amistad, la vecindad u otro tipo de afiliaciones organizacionales (trabajo, ocio, etc.) y son fundamentales para el reclutamiento y la movilización de nuevas personas (Mische 2003: 260). En definitiva, estamos 
hablando del proceso de "reclutamiento" (Snow, Zurcher and Ekland-Olson, 1980), o de "difusión" McAdam (2003), es decir, cuando la propagación del movimiento se realiza a lo largo de las líneas preestablecidas de interacción.

En lo que respecta al mecanismo de desacoplamiento, daría forma a lo que Melucci identificaba como el paso de la acción colectiva "latente" a la acción colectiva "visible" (Melucci 1989: 70-73). Cuando lo instituyente deja de ser un mero "fluir", "sentir" o "pensar" para convertirse en una acción dotada de cierta racionalidad, es decir, con objetivos más o menos definidos. "Cuando un colectivo emerge con respecto a la red que le ha dado origen, él se desacopla: mientras que al comienzo su funcionamiento es totalmente dependiente de la red..., gracias a los recursos de mediación, él adquiere una relativa autonomía...» (Grossetti 2009: 52).

En este sentido, la idea fundamental que permite hablar de la existencia de un nuevo movimiento social es el hecho de que un actor colectivo, además de estar desacoplado de las redes sociales que permitieron su nacimiento y, además de ser visible, adopte un cierto grado de organización (Snow and Oliver 1995: 571). Aunque no se pueden equiparar movimiento social y organización formal, sí es lícito decir que, para poder hablar de un movimiento social, se precisa algún tipo de organización (formal o informal) que haga posible diseñar, transmitir y hacer operativos objetivos, estrategias y actuaciones (McAdam, McCarthy y Zald 1999: 24 y ss.).

\section{LA METODOLOGÍA DE LA INVESTIGACIÓN}

Nuestra aproximación metodológica es muy concreta: el estudio de caso. Existe un acuerdo en que el fundamento del estudio de caso se centra en la realización de un análisis en profundidad y sistemático de un fenómeno "situado" y delimitado en la realidad social, tanto desde el punto de vista espacial como temporal (Rodríguez, Gil y García 1996). Igualmente, otra de las características del estudio de caso es compartir un mismo periodo histórico con el investigador que lleva a cabo el estudio (Yin 2003).

El estudio de caso se incluye dentro de las tradiciones de investigación cualitativa, pero se diferencia del resto de perspectivas que también forman parte de ella (biográfica, fenomenológica, teoría fundamentada y etnografía) en varios aspectos y, en concreto, en que, en lo referido al estudio de caso, los procedimientos para alcanzar la validez son dos (según Stake 2005). Por un lado, la triangulación, consistente en la aplicación de múltiples técnicas de investigación en un mismo caso (Ayoub, Wallace and Zepeda-Millán 2014). Y por otro, la confirmación de los participantes, es decir, que estos se vean reflejados en las conclusiones extraídas de la investigación.
En consecuencia, para estudiar la génesis de GZ, se ha procedido a aplicar diferentes técnicas de investigación en función de los niveles objeto de análisis: análisis de documentación (páginas web, actas, etc.), siete entrevistas semidirigidas a informantes clave y una encuesta estadística representativa.

Las entrevistas se focalizaron en aquellos agentes que tuvieron un protagonismo en las primeras fases del movimiento, en el tercer trimestre de 2014. Su pertenencia previa a las redes analizadas era la siguiente: uno se identificó a sí mismo como "impulsor", es decir, que participó en las reuniones previas para dar inicio a este movimiento (aunque es un destacado activista de los movimientos ecológicos); otro pertenecía a un partido político (Izquierda Unida); dos pertenecían a un movimiento enfocado a conseguir la unidad de la izquierda en Zaragoza (Ateneo); dos a movimientos sociales (uno medioambiental - Pedalea - y otro de impulso democrático - Movimiento por la Democracia-) y, finalmente, otro entró directamente a través del impulsor citado anteriormente.

El análisis de las entrevistas sirvió, fundamentalmente, para abrir el campo de investigación, conocer las redes (o grupos) preexistentes que habían formado parte de este movimiento y para obtener información de las relaciones con otros movimientos similares que se estaban produciendo en otras ciudades españolas.

Respecto a la encuesta, se escogió la lista "municipalismo"3, que se creó en los primeros momentos de vida de GZ y a la que se iban sumando todas las personas que se vinculaban al movimiento, procedentes de diferentes vías de captación. Fue especialmente importante en la gestación, consolidación y desborde de GZ y es considerada como la lista principal y básica que incluye a las "fuerzas vivas de GZ". En ella se encontraban inscritas 554 personas a 1 de junio de 2015. La muestra que finalmente contestó fue de 253 , con lo que se obtuvo un margen de error del $+/-4,5 \%$ y un nivel de confianza del $95 \%$.

A este conjunto de personas se les pasó un cuestionario cuya administración fue online. Por lo tanto, la encuesta fue "autoadministrada" y su diseño tuvo en consideración los requisitos de esta modalidad de administración de cuestionarios (Díaz de Rada 2012: 195).

Respecto a la validación de los resultados, se celebró un grupo de trabajo con ocho personas que reunían las dos siguientes condiciones: que hubiesen estado inscritas en la lista de municipalismo antes del 31 de octubre de 2014 y que representasen una variedad de perfiles respecto a su pertenencia previa a organizaciones presentes en la génesis de GZI ZeC. En la sesión de trabajo se procedió a la presentación de las principales conclusiones de la investigación, se abrió un debate en el que contrastaron sus impresiones $\mathrm{y}$, posteriormente, respondieron de 
forma anónima a un breve cuestionario compuesto por ocho preguntas, centradas en las principales conclusiones de la investigación. La valoración de los participantes (que podían puntuar cada pregunta entre 1 y 5) arroja unos valores medios que se sitúan, en todas ellas, entre el 4 y el 5 , alcanzando la media un valor de 4,45.

\section{Breve historia de Ganemos Zaragoza y ANÁLISIS DE RESULTADOS}

Realizar una historia completa de GZ excede con mucho las pretensiones de este artículo, ya que pasaría necesariamente por profundizar en los elementos contextuales que crearon el clima social, político y económico necesario para activar el nacimiento de este nuevo movimiento. Igualmente, sería obligatorio analizar la evolución del tejido político y social al calor del impacto del $15 \mathrm{M}$, tal y como se ha comentado anteriormente. En este artículo nos vamos a ceñir a presentar los hechos más significativos en la génesis de GZ, cuyo desarrollo se puede consultar en Minguijón (2016):

1. Reuniones previas de líderes sociales, políticos y sindicales, a las que se invitaban a personas relevantes del tejido asociativo de la ciudad (junio de 2014). Se han identificado cuatro iniciativas diferentes: Movimiento por la Democracia, la de un líder del movimiento ecologista, la del movimiento por la unidad de la izquierda (Ateneo) y la de un conglomerado de sindicalistas, afiliados a IU y miembros de Stop Desahucios.

2. Primera reunión abierta, en la que confluyeron las tres primeras de esas iniciativas y decidieron impulsar el proceso de forma conjunta (10 de julio de 2014).

3. Primera asamblea de Ganemos Zaragoza (18 de agosto de 2014), abierta a toda la ciudadanía. A partir de aquí, se celebraron un sinfín de asambleas en las que el movimiento iba tomando forma, creando comisiones, fijando objetivos, ampliando su base social.

4. Presentación pública ante la sociedad zaragozana de Ganemos Zaragoza (20 de noviembre de 2014).". Se inician contactos formales con fuerzas políticas afines con el objetivo de alcanzar la confluencia.

5. Decisión de Ganemos Zaragoza de acudir en coalición (16 de diciembre de 2014).”.

6. Cambio de nombre a Zaragoza en Común ( 18 de febrero de 2015).

7. Primarias abiertas (Zaragoza en Común) (finales de febrero de 2015).

8. Constitución del partido instrumental Partido GZ para incorporarse a la coalición ( 8 de abril de 2015).
9. Elecciones municipales del 25 de mayo de 2015. Se consiguen 9 de los 31 concejales y se alcanza el gobierno de la ciudad.

Vista esta sucesión temporal, es preciso resolver las posibles dudas que pudieran existir en torno a la clasificación de Ganemos Zaragoza / Zaragoza en Común como un movimiento social o como una organización política. Nuestra hipótesis es que, atendiendo a su evolución, podrá tomar uno u otro calificativo y que sólo revisando las fechas claves de su evolución podremos establecer el momento en el que el proceso analizado deja de tener las características de un movimiento social para convertirse en un partido político. Hemos identificado ese momento como el paso de la formalización del partido Ganemos Zaragoza (8 de abril de 2015). Ese es el momento en el que GZ/ZeC cambia desde una situación de "extra-institucional disruption" a otra de "electoral representation" (Kitschelt 2006:281). Esta situación híbrida, que en ese trabajo Kitschelt denominó "Movement Partie", ha sido analizada más profusamente por Porta, Fernandez, Kouki y Mosca (2017), y es la óptica adoptada por Martín (2015) para explicar el ser de las confluencias.

Llega ahora el momento de analizar la evolución de $\mathrm{GZ} / \mathrm{ZeC}$ atendiendo a las fases contempladas en el marco teórico. En relación con la fase de acoplamiento, los primeros pasos de GZ se producen en el verano de 2014, cuando un grupo de personas, con un relevante liderazgo en la comunidad zaragozana y pertenecientes a organizaciones de diversa índole, aprovecharon los espacios de encuentro rutinarios en sus actividades para comenzar una serie de de contactos informales en los que aparece la necesidad y conveniencia de afrontar la situación social a través de nuevas respuestas colectivas.

Este proceso, descrito por Mische (2003), se asemeja al de intermediación identificado por McAdam (2003) y, en nuestro caso, atendiendo al análisis de las entrevistas que abrieron el campo de investigación, así como a los resultados del cuestionario cumplimentado por las personas que se declaran como pertenecientes al "núcleo impulsor" (en concreto, diez personas de la muestra), podemos afirmar que se produjeron asiduos contactos con los procesos de Ganemos Barcelona y Ganemos Madrid, lo que catalizó el interés de ciertos líderes de movimientos sociales de Zaragoza por impulsar un movimiento similar en esta ciudad. En este caso, se puede observar con claridad el efecto de contagio entre procesos similares en ciudades distintas y el papel de las redes "meso" compuestas por líderes capaces de hacer circular determinadas estrategias propias de los movimientos en diferentes lugares (Hedström 1994). Las redes preexistentes identificadas como pertenecientes a esa realidad supramunicipal que permitieron la imitación y réplica de procesos a escala nacional han sido: Movimiento por la Democracia, 
Izquierda Unida, el movimiento ecologista, Marchas por la Dignidad y Stop Desahucios.

Estos vínculos y negociaciones son esenciales en el proceso de acoplamiento de las redes preexistentes. A este respecto, se detecta un proceso de integración de redes de organizaciones preexistentes (desde el verano de 2014 hasta febrero de 2015). Redes que ya venían funcionando en la ciudad de Zaragoza y que son activadas por sus miembros para promover o facilitar el proceso de generación de GZ.

Hay que señalar que en el grupo promotor de GZ que está siendo analizado estaban presentes 43 líderes orgánicos de estas organizaciones ( $17 \%$ de la muestra), lo que fue sustancial para conseguir su alineación estratégica en este proceso.

En esta fase es preciso realizar una distinción entre: a) la creación de alianzas "explícitas" entre redes organizativas preexistentes, protagonizadas fundamentalmente por los partidos políticos que finalmente entraron en la coalición electoral (Izquierda Unida, Puyalón, Equo, Piratas de Aragón, Demos + y Somos ${ }^{4}$ ), además del apoyo de Podemos; y b) la integración en el movimiento, de facto, de otra serie de redes organizativas. En la encuesta se han detectado 41 redes organizacionales implicadas en la génesis de GZ (incluyendo las del apartado anterior): 11 pertenecían al movimiento sindical, 9 a partidos políticos, 8 a mareas, además de otras redes significativas, como las asociaciones de vecinos, el movimiento ecologista, la Plataforma de Afectados por las Hipotecas, Democracia Real Ya, la Fundación de los Comunes, etc. Igualmente, se identificaron otras asociaciones con una baja presencia y que no fueron trabajadas de forma independiente por su escasa transcendencia para el movimiento naciente.

Diecisiete de las 41 identificadas, es decir, un 41,5 $\%$, tienen una representación igual o superior a los diez miembros en la muestra.

Los resultados de la encuesta evidencian que más de la mitad $(52,2 \%)$ de las personas analizadas entró en el movimiento a través de alguna de esas redes, aunque 13 personas no pertenecian formalmente a ninguna de ellas. Asimismo, el 47,8 \% entró a través de otras fórmulas, ya fuesen las relaciones personales $(20,2 \%)$, las redes sociales $(15,4 \%) \mathrm{u}$ otra vía $(8,3 \%)$.

Estos resultados confirman la propuesta de Mario Diani, ya sugerida por Tarrow (1998: cap.3), en torno a que «las organizaciones históricamente han sido la fuente más importante de continuidad, confianza y reconocimiento mutuo de sus miembros. Y es a través

Figura 2.

Proceso de integración a través de redes de movimientos sociales previas u otras fórmulas

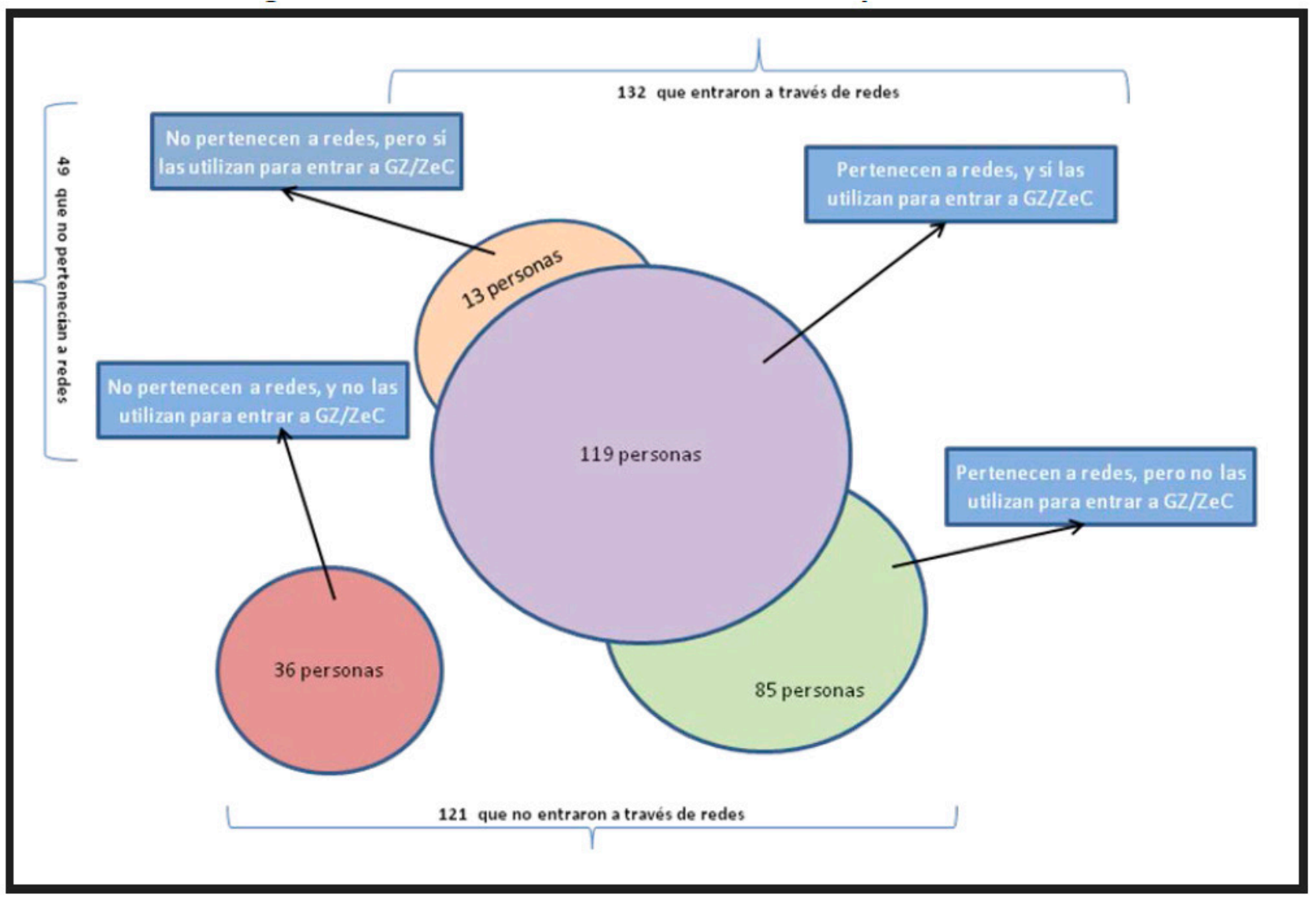

Fuente: Elaboración propia. 
de sus redes sistemáticas como los movimientos sociales modernos han surgido y se han consolidado...» (Diani 2015: 13).

Respecto a la fase de desborde, se han analizado las vías a través de las cuales los miembros de la lista "municipalismo" fueron captando a nuevos adeptos. En este sentido, el 89,3 \% de ellos manifiesta que hizo de puente a la incorporación de nuevos miembros.

Tabla I.

Vías a través de las que ha hecho de puente de entrada a GZ/ZeC

\begin{tabular}{|l|c|}
\hline Vías ha hecho de PUENTE & Porcentaje \\
\hline Familiar & $53,5 \%$ \\
\hline Amigo & $83,0 \%$ \\
\hline Compañero de trabajo & $34,5 \%$ \\
\hline Compañero de estudios & $9,5 \%$ \\
\hline Compañero de partido, asoc., sindicato... & $15,0 \%$ \\
\hline TOTAL & 200 \\
\hline
\end{tabular}

Fuente: Encuesta propia. Lista "municipalismo" de GZ/ZeC. Base: 200. Una persona puede hacer de puente en varias categorías.

El panorama cambia sensiblemente respecto a la fase anterior, perdiendo relevancia las redes preexistentes a favor de otro tipo de vías, como la amistad, que ha sido la principal vía de expansión y desborde, siendo utilizada por el $83 \%$ de los que hicieron de puente. Le siguen las relaciones familiares $(53,5 \%)$, los contactos del trabajo (34,5\%) y de los estudios $(9,5 \%)$. Las redes organizacionales solo representan un $15 \%$ en este proceso de desborde, cifra muy alejada de lo que significó al principio del proceso.

Por lo tanto, se puede concluir que las redes formales de diversos tipos (sociales, políticas y sindicales) fueron determinantes en las fases iniciales de $\mathrm{GZ}$, aunque en la fase de desborde o de expansión tomaron relevancia las redes informales de tipo familiar, de amigos o de compañeros de trabajo.

Respecto a la fase de desacoplamiento, se debe volver la mirada al proceso de formalización de GZ/ ZeC, desde una organización con claros tintes de informalidad inicial hasta una organización plenamente formalizada que se presentó como coalición a las elecciones municipales de 2015. Con base en el análisis realizado, son tres los hechos principales que fueron marcando el proceso de desacoplamiento: la presentación pública de Ganemos Zaragoza el 20 de noviembre de 2014; la decisión de crear el partido instrumental Ganar Zaragoza (para entrar en la coalición como un partido más) el 16 de diciembre de 2014 (finalmente constituido el 8 de abril del año siguiente), y el cambio de nombre a Zaragoza en Común, decisión adoptada en el plenario de 18 de febrero de 2015.
Cada uno de esos hechos va permitiendo el paulatino paso desde un movimiento social claramente reconocible a una organización política. Pero ni siquiera la formalización del partido y de la coalición provocó la pérdida de influencia de las redes preexistentes en GZ/ZeC. De hecho, transcurridos tres años de ejercicio del gobierno en la ciudad, todavía se puede comprobar su influjo cotidiano en Zaragoza en Común, por lo que no puede afirmarse que se ha llegado al desacoplamiento total.

Interesa a continuación analizar la articulación entre las redes identificadas. Utilizando el programa estadístico UCINET, se han identificado cuatro clústeres a través de un análisis específico ("optimización tabú") que se basa en agrupar en un mismo conglomerado aquellos actores que tienen una forma de relacionarse con el resto de actores muy parecida (Glover 1989; 1990) y, por lo tanto, se puede deducir que están jugando dentro de la red un papel semejante (los miembros del mismo clúster han tenido una "carrera organizativa" similar).

Uno de esos clústeres estaba previamente definido como la ausencia de redes (o de redes minoritarias sin interconexión con otras a través de sus miembros), que representaba al $24,1 \%$ de los miembros de la muestra.

De los tres clústeres restantes, se han identificado las redes sobre las que pivotan:

Clúster "movimientos reivindicativos": Marea Verde $(\mathrm{V})$ y Asociaciones de Vecinos (AV), que representa al $26,5 \%$ de los encuestados y el 39,0 $\%$ de los lazos presentes. Otras redes significativas son la Marea Negra (N) y la Blanca (BI).

Figura 3.

Relaciones predominantes en el clúster "movimientos reivindicativos"

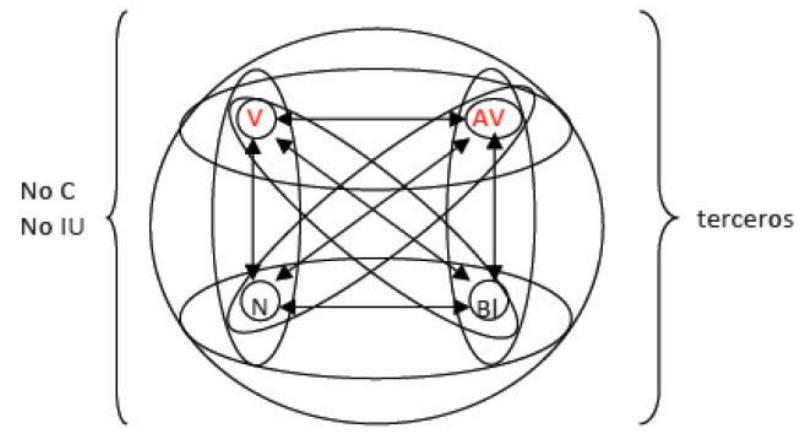

- Clúster "nueva izquierda": movimientos ecologistas (E) y Podemos (POD), que representa al 15 $\%$ de los miembros de la muestra y el $13,7 \%$ de los lazos.

A esos dos hay que añadir, con menor trascendencia en el clúster, el partido Puyalón (PUY), los sindicatos SOA y Unión General de Trabajadores (UGT) y el Movimiento por la Democracia (MPD) 
Figura 4.

Relaciones predominantes en el clúster "nueva izquierda"

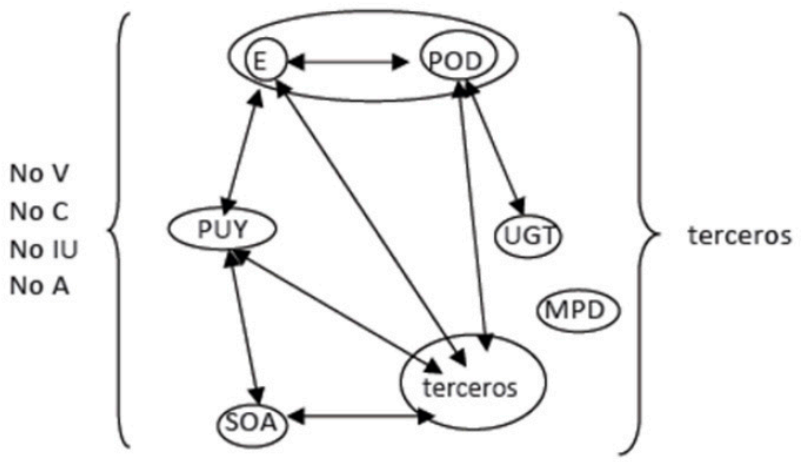

- Clúster "izquierda tradicional": Izquierda Unida (IU) y Comisiones Obreras (C), que representa al $34,4 \%$ de los encuestados y el $47,3 \%$ de los lazos.

Figura 5

Relaciones predominantes en el clúster "izquierda tradicional"

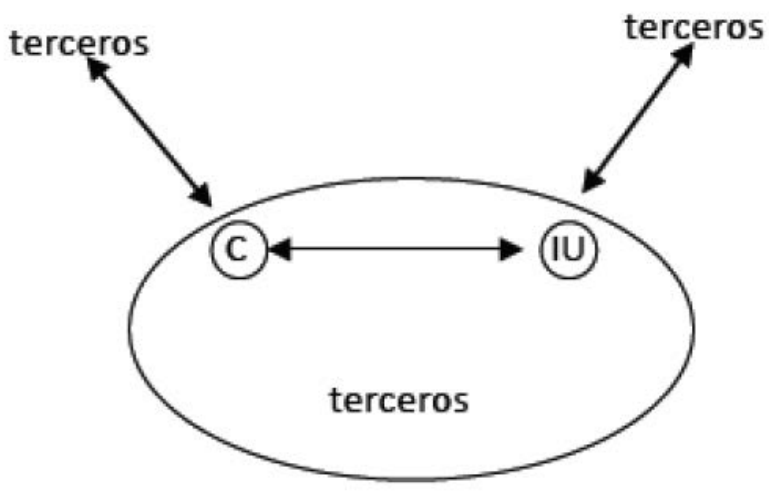

A partir de ellas, se establecieron relaciones mucho más heterogéneas y variadas con el resto de redes y organizaciones que estuvieron presentes en la génesis de GZ. Estas vinculaciones no se presentaban de forma tan frecuente en la muestra analizada, pero cumplieron la función de extender los tentáculos del movimiento a otras personas.
Respecto al momento en el que se produjo la integración de estas personas en $\mathrm{GZ} / Z e C$, se pueden destacar los siguientes datos: los miembros de la "izquierda tradicional" se integraron en el movimiento en la fase de acoplamiento en mayor medida que el resto; le siguieron los de "nueva izquierda". En la fase de desborde es cuando se produjo la entrada masiva de la totalidad de los clústeres, pero destacan los "movimientos reivindicativos", la "nueva Izquierda" y los "no asociados". En la de desacoplamiento tienen mayor presencia los "no asociados" y los de la "izquierda tradicional".

Puede observarse que, en un primer momento, los clústeres formados por los partidos políticos tuvieron mayor importancia. Posteriormente, GZ/ZeC se fue nutriendo de los nuevos movimientos y partidos, como las Mareas y Podemos, a los que habría que añadir el movimiento ecologista y las asociaciones de vecinos. $Y$ finalmente, cuando $\mathrm{GZ} / \mathrm{ZeC}$ fue adquiriendo mayor grado de formalización, el movimiento se fue extendiendo principalmente a través de personas sin pertenencia previa y de Izquierda Unida y Comisiones Obreras.

Respecto al proceso de desborde o expansión, los miembros del clúster "movimientos reivindicativos" destacan respecto del resto en que han hecho de puente en mayor medida a través de la red familiar $(53,7 \%)$ y de las redes políticas, asociativas y sindicales $(16,4 \%)$. El clúster "nueva izquierda" destaca en las redes familiares $(86,8 \%)$ y en las laborales $(39,5 \%)$. El clúster "izquierda tradicional" lo hace en las redes familiares $(51,7 \%) \mathrm{y}$, en menor medida, en las de movimientos (13,8\%). Finalmente, el clúster de "no asociados" se caracteriza por mantener una escasa actividad de expansión del movimiento.

Otra cuestión estudiada es la identificación de los actores más relevantes en la construcción de este movimiento. Para ello, se hallaron los índices de grado $^{5}$, cercanía ${ }^{6}$ e intermediación ${ }^{7}$. Un análisis de los mismos lleva a la conclusión de que, entre los 20 actores con mayor capacidad de intermediación, 15 pertenecen a la Marea Verde, 10 a asociaciones de vecinos, 10 a movimientos ecologistas, 10 a Marchas por la Dignidad y 9 a Podemos.

Tabla II.

Clúster de entrada en función de la fase de entrada en GZ

\begin{tabular}{|l|c|c|c|c|}
\hline & \multicolumn{4}{|c|}{ Fase de ENTRADA } \\
\hline Vías de ENTRADA & Acoplamiento & $\begin{array}{c}\text { Desborde } \\
\text { Expansión }\end{array}$ & Desacoplamiento & TOTAL \\
\hline Mov. reivindicativos & $10,3 \%$ & $79,3 \%$ & $10,3 \%$ & 58 \\
\hline Nueva izquierda & $19,7 \%$ & $72,7 \%$ & $7,6 \%$ & 66 \\
\hline Izquierda tradicional & $32,4 \%$ & $51,4 \%$ & $16,2 \%$ & 37 \\
\hline No asociados & $10,7 \%$ & $69,0 \%$ & $20,2 \%$ & 84 \\
\hline TOTAL & $16,3 \%$ & $69,8 \%$ & $13,9 \%$ & 245 \\
\hline
\end{tabular}

Fuente: Encuesta propia. Lista "municipalismo" de GZ/ZeC. Base: 245 (8 Ns/Nc) 
Tabla III.

Vías a través de las que ha hecho de puente a GZ, atendiendo a los clústeres de pertenencia

\begin{tabular}{|l|c|c|c|c|c|}
\hline & \multicolumn{5}{|c|}{ Vías de EXPANSIÓN } \\
\hline CLÚSTER de pertenencia & Familiar & Amigo & $\begin{array}{c}\text { Com. } \\
\text { Trabajo }\end{array}$ & $\begin{array}{c}\text { Com. } \\
\text { Estudios }\end{array}$ & Com. PIA/S... \\
\hline Mov. reivindicativos & $53,7 \%$ & $73,1 \%$ & $32,8 \%$ & $9,0 \%$ & $16,4 \%$ \\
\hline Nueva izquierda & $44,7 \%$ & $86,8 \%$ & $39,5 \%$ & $7,9 \%$ & $10,5 \%$ \\
\hline Izquierda tradicional & $51,7 \%$ & $75,9 \%$ & $28,7 \%$ & $6,9 \%$ & $13,8 \%$ \\
\hline No asociados & $14,8 \%$ & $29,5 \%$ & $11,5 \%$ & $6,6 \%$ & $4,9 \%$ \\
\hline TOTAL & $42,3 \%$ & $65,6 \%$ & $27,3 \%$ & $7,5 \%$ & $11,9 \%$ \\
\hline
\end{tabular}

Fuente: Encuesta propia. Lista "municipalismo" de GZ. Base: 253

Una persona puede hacer de puente en varias categorias.

Por otra parte, los actores con mayores índices de centralidad solo coinciden en cuatro ocasiones con los que ejercían algún puesto de responsabilidad en las redes preexistentes (que, recordemos, eran 43 en la muestra). Eso quiere decir que, visto globalmente el proceso, y aunque en un principio pudiesen tener un papel esencial tejiendo alianzas, en lo que respecta al fenómeno global (desde su comienzo hasta su desacoplamiento), su papel no ha sido más relevante que el que han podido jugar otros actores con menor poder orgánico en las redes a las que pertenecían.

\section{COMENTARIO CRÍtICO Y CONCLUSIONES}

El recorrido analítico llevado a cabo a través del estudio de caso ha permitido contrastar, bajo el paradigma relacional, el proceso de generación de una nueva formación política como evolución de un movimiento social nacido al calor del 15M, ofreciendo una evidencia científica que ha superado la, ya de por sí, evidente importancia de las redes en los movimientos sociales, abordando la tarea de demostrar empíricamente "qué redes explican qué" y "bajo qué condiciones las redes concretas adquieren importancia".

A lo largo de las reflexiones anteriores se ha podido comprobar cómo este movimiento se tejió a partir de unas redes preexistentes, que terminaron por construir la malla relacional desde la que se fue edificando y fortaleciendo. Se ha comprobado cómo las redes organizativas tuvieron importancia en la fase de acoplamiento, mientras que en la de desborde fueron adquiriendo mayor relevancia las redes menos formales y más características de la vida cotidiana de los individuos. De esta forma, se han contrastado las vías a través de las cuales fue creciendo el movimiento, permitiendo el tránsito de activistas, militantes y personas sin activación política previa desde los movimientos sociales a la política.

Igualmente, se ha podido evidenciar que no todas las redes jugaron el mismo papel a lo largo del proceso, ya que se articularon formando varios conglomerados que tuvieron diferente nivel de activación en las distintas fases de gestación de GZ/ ZeC. También que el movimiento naciente creó sus propios liderazgos más allá de los que procedían de las organizaciones preexistentes.

Desde la aproximación teórica propuesta, se ha centrado el análisis en la perspectiva relacional, dejando de lado otras dimensiones que, sin duda, fortalecerían la comprensión global del nacimiento de $\mathrm{GZ} / Z e C$. Especialmente importante hubiera sido ahondar en el análisis de los aspectos contextuales de carácter social, económico y político, tanto a escala local como nacional e internacional. Igualmente, se podría haber profundizado en la comprensión de la interacción entre el 15M y el surgimiento de $G Z$, en lo que se refiere a aspectos discursivos que pasaron a formar parte del mensaje y de las propuestas de este movimiento, así como en lo relativo a la "activación política" de algunos de los jóvenes que se integraron en $\mathrm{GZ}$ o, algo que se ha comentado sucintamente, la transformación del tejido de los movimientos sociales de la ciudad.

En consecuencia, en este estudio se ha obrado haciendo abstracción de todo elemento que perturbase el objetivo de fijar la atención en el papel de las redes, su interacción y evolución, por lo que no deja de ser un análisis en cierta medida limitado, lo que aconsejaría en el futuro fortalecerlo con una perspectiva más plural.

\section{Agradecimientos}

El artículo presentado tiene su base en un programa de investigación sobre la participación sociopolítica llevado a cabo desde el año 2009. Se inició con objeto de varios estudios sociológicos financiados por Aragón Participa del Gobierno de Aragón. A continuación se investigó sobre el 15-M, y finalmente se ha realizado el presente estudio. 


\section{NOTAS}

1. Para un repaso analítico de los diferentes usos de la noción de red, ver Maillochon (2010).

2. La capacidad de las redes sociales de transmitir y "alojar" recursos a lo largo de la estructura social, ya fue puesta de manifiesto por Wellman y Berkowitz (1988: 20 y ss.).

3. Había otras dos listas: la del "plenario", creada en una fase muy avanzada (febrero de 2015), que contenía a las personas implicadas en tareas operativas dentro de la organización y la de la "asamblea", de las que formaba parte las personas con derecho a voto, muchas de las cuales entraron en fechas tardías y no participaban activamente en el movimiento.

4. Puyalón es un partido independentista aragonés, creado en 2009 como una escisión de Chunta Aragonesis-

\section{Referencias Bibliográficas}

Aguiló, A. y J. Sabariego. 2016. "Epistemologies of the south and local elections in Spain: towards politics based on the commons?". Historia Actual Online 40 (2): 95-111.

Amenta, E. 2014. "How to Analyze the Influence of Movements". Contemporary Sociology: A Journal of Reviews 43 (1): 16-29. https://doi.org/10.1177/0094306113514536

Amenta, E. y N. Caren. 2013. "Outcomes, political", en The Wiley-Blackwell Encyclopedia of Social and Political Movements, editado por D. A. Snow, D. della Porta, B. Klandermans and D. McAdam. Oxford: Blackwell. https://doi.org/10.1002/9780470674871.wbespm441

Anduiza, E., I. Martín y A. Mateos. 2013. "The consequences of the 15-M protests on voting choice in the 2011 Spanish General Elections", EPSA Conference.

Ayoub, P. M., S. J. Wallace y C. Zepeda-Millán. 2014. "Triangulation in social movement research". Pp. 67-96 en Methodological Practices in Social Movement Research, D. della Porta. comp. Oxford: Oxford University Press. https://doi.org/10.1093/acprof:o so/9780198719571.003.0004

Bidart, C., A. Degenne y M. Grossetti. dir. 2011. La vie en réseau. Dynamique des relations sociales. Paris: Presses Universitaires de France.

Calle, A. 2015. «Podemos y el auge municipalista. Sobre partidosciudadanía y vieja política». EMPIRIA. Revista de Metodología de Ciencias Sociales 32:169-190. https:// doi.org/10.5944/empiria.32.2015.15313

Casanueva, A. 2014. "Can social movements change political outcomes? Evidence from 15M Movement in Spain". ECPR General Conference, Université de Montréal (https://ecpr.eu/Filestore/PaperProposal/bc71d18655ed-4fba-8eb7-9ee4c915be7c.pdf)

Castells, M. 2005. La Era de la Información (Vol.I). Economía, Sociedad y Cultura. La Sociedad Red. Madrid: Alianza Editorial.

Castells, M. 2012. Redes de indignación y esperanza. Madrid: Alianza Editorial.

Charlot, J. 1971. Les partis politiques. París: Colin.

Christakis, N. A. y J. H. Fowler. 2010. Conectados. Madrid: Taurus.

Crossley, N. 2002. Making Sense of Social Movements. Buckingham/Philadelphia: Open University Press.

Crossley, N. 2011. Towards Relational Sociology. London and New York: Routledge.

Crossley, N. and J. Krinski. 2015. Social Networks and Social Movements. London: Routledge. ta $(\mathrm{CHA})$. Piratas de Aragón es un partido de ámbito estatal, creado en 2007, interesado en nuevas tecnologías, la Red y la defensa de las libertades civiles en el mundo digital. Además, Demos +, implicado en la democracia directa, fue creado en 2013. Somos fue creado en junio de 2013.

5. Definido como los vínculos directos (sin intermediación) que posee un determinado actor.

6. Entendido como la accesibilidad de un actor (o red) al resto de actores (o redes) a través de los caminos más cortos (distancia geodésica), es decir, incluyendo los caminos con intermediarios.

7. Es la suma de las probabilidades estimadas de que un actor esté "implicado" en la comunicación (geodésica) entre dos actores, sin incluir a ese actor.

Cruz, J. 2014. "Asaltados o asaltantes: municipalismo y movimientos sociales en la coyuntura electoral". Youkali: revista crítica de las artes y el pensamiento 17: 17-22

Diani, M. 1998. "Las redes de los movimientos sociales: una perspectiva de análisis". Pp. 243-270 en Los movimientos sociales. Transformaciones políticas y cambio cultural, editado por P. Ibarra y B. Tejerina. Madrid: Trotta.

Diani, M. 2003. "Networks and Social Movements: A Research Programme". Pp. 299-319 en Social movement and networks. Relational approaches to collective action, editado por M. Diani, and D. McAdam. New York: Oxford University Press. https://doi. org/10.1093/0199251789.003.0013

Diani, M. 2004. "Networks and Participation". Pp. 339359 en The Blackwell Companion to Social Movements, editado por D. A. Snow, S. A. Soule and H. Kriesi. Oxford: Blackwell Publishing. https://doi. org/10.1002/9780470999103.ch15

Diani, M. 2015. "Revisando el concepto de movimiento social". Encrucijadas. Revista Crítica de Ciencias Sociales 9: 1-16.

Diani, M. y D. McAdam. eds. 2003. Social Movements and Networks. Oxford/New York: Oxford University Press. https://doi.org/10.1093/0199251789.001.0001

Díaz-Parra, I. y J. Jover-Báez. 2016. "Social movements in crisis? From the 15-M movement to the electoral shift in Spain", International Journal of Sociology and Social Policy. 36 (9/10): 680-694. https://doi.org/10.1108/IJSSP-09-2015-0101

Díaz de Rada, V. 2012. "Ventajas e inconvenientes de la encuesta por Internet". Papers, 97(1): 193-223. http:// dx.doi.org/10.5565/rev/papers/v97n1.71

Donati, P. 1993. "Pensamiento sociológico y cambio social: hacia una teoría relacional". Revista Española de Investigaciones Sociológica 63: 29-51.

Donati, P. 2006. Repensar la sociedad. El enfoque relacional. Madrid: Ediciones Internacionales Universitarias.

Donati, P. 2011. Relational sociology: a new paradigm for the social sciences. London: Routledge.

Donati, P. 2015. "Manifesto for a critical realist relational sociology". International Review of Sociology: Revue Internationale de Sociologie 25 (1): 86-109. https://doi.org/ 10.1080/03906701.2014.997967

Duverger, M. 1980. Los partidos políticos. México: Fondo de Cultura Económica. 
Emirbayer, M. 1997. "Manifest for a Relational Sociology". American Journal of Sociology 103 (2): 281-317. https://doi.org/10.1086/231209

Emirbayer, M. y J. Goodwin. 1994. "Network Analysis. Culture and the Problem of Agency". American Journal of Sociology 99 (6): 1411-1454. https://doi.org/10.1086/230450

Emirbayer, M. y A. Mische 1998. "What is Agency?". American Journal of Sociology 103: 962-1023. https://doi. org/10.1086/231294

Fernández-Llebrez, F. 2015. "A vueltas con las "candidaturas unitarias" y el cambio electoral". Consulta el 28 de julio de 2017 (https://es.scribd.com/ document/273778695/A-vueltas-con-las-candidaturas-unitarias-y-el-cambio-electoral-Fernando-Fernandez-Llebrez).

Freeman, L. C. 1992. "Social Networks and the Structure Experiment". Pp. 11-40 en Research Methods in Social Network Analysis, editado por L.C. Freeman, D.R. White and A.K. Romney. New Brunswick (USA), Londres: Transaction Publishers.

Gerbaudo, P. 2012. Tweets and the Streets. Social Media and Contemporary Activism. London: Pluto Press.

Giugni, M., L. Bosi y K. Uba. eds. 2016. The Consequences of Social Movements. Cambridge/ New York: Cambridge University Press.

Glover, F. 1989. "Tabu Search - Part I". ORSA Journal on Computing 1: 190-206. https://doi.org/10.1287/ijoc.1.3.190

Glover, F. 1990. "Tabu Search - Part II". ORSA Journal on Computing 2: 4-32. https://doi.org/10.1287/ijoc.2.1.4

Grossetti, M. 2009. “¿Qué es una relación social? Un conjunto de mediaciones diádicas". REDES- Revista hispana para el análisis de redes sociales, 6 (2): 44-61.

Hedström, P. 1994. "Contagious collectivities: on the spatial diffusion of Swedish trade unions, 1890-1940". American Journal of Sociology 99: 1157-79. https://doi. org/10.1086/230408

Hedström, P., R. Sandell y C. Stern. 2000. "Mesolevel Networks and the Diffusion of Social Movements: The Care of the Swedish Social Democratic Party". American Journal of Sociology 106:145-172. https://doi. org/10.1086/303109

Hoz, León de la (2015): Los indignados españoles: del 15M a Podemos. Madrid: Betania.

Johnston, H. 2011. States and Social Movements. Cambridge: Polity Press.

Kitschelt, H. 2006. "Movement Parties". Pp. 278-290 en Handbook of Party Politics, editado por R. H. Katz y W. Crotty. London: SAGE Publications, https://doi. org/10.4135/9781848608047.n24

Klandermans, B. y D. Oegema. 1987. "Potentials, Networks, Motivations, and Barriers: Steps Towards Participation in Social Movements". American Sociological Review 52: 519-531. https://doi.org/10.2307/2095297

Laraña, E. 1999. La construcción de los movimientos sociales. Madrid: Alianza Editorial.

Maillochon, F. 2010. "Pourquoi l'analyse des réseaux?". Pp. 187-206 en L'enquête sociologique, editado por S. Paugam. Paris: PUF.

Martín, I. 2015. «Podemos y otros modelos de partido-movimiento», Revista Española de Sociología 24: 107-114.

Martínez, M. y E. Domingo. 2014. "Los impactos sociales y políticos del Movimiento 15M en España". http://www.miguelangelmartinez.net/?Social-and-political-impactsof [Consultado el 20/08/2016].

McAdam, D. 2003. "Beyond structural analysis: toward a more dynamic understanding of social movements". Pp. 281-
298 en Social Movements and Networks, editado por M. Diani y D. McAdam. Oxford/New York: Oxford University Press. https://doi.org/10.1093/0199251789.003.0012

McAdam, D., J. McCarthy y M. Zald 1999. Movimientos sociales: perspectivas comparadas. Madrid: Ediciones Istmo.

McAdam D. y R. Paulsen 1993. "Specifying the Relationship between Social Ties and Activism". American Journal of Sociology 99: 640-647. https://doi.org/10.1086/230319

McAdam, D., S. Tarrow y C. Tilly 2001. Dynamics of Contention. Cambridge: Cambridge University Press.

Melucci, A. 1989. Nomads of the Present: Social Movements and Individual Needs in Contemporary Society. London: Hutchinson.

Melucci, A. 1994. "¿Qué hay de nuevo en los nuevos movimientos sociales?". Pp. 119-150 en Los nuevos movimientos sociales. De la ideología a la identidad, editado por E. Laraña y J. Gusfild. Madrid: CIS.

Meyer, D. S. and N. Whittier 1994. "Social Movement Spillover". Social Problems 41 (2): 277-298. https://doi. org/10.1525/sp.1994.41.2.03x0438v

Minguijón, J. 2016. "La génesis de Ganemos Zaragoza. Un estudio desde la sociología relacional". Tesis doctoral, Departamento de Psicología y Sociología, Universidad de Zaragoza.

Mir, J. 2015. "La revolución democrática desde abajo en el municipalismo: ciudadanía, movimientos sociales y otra manera de hacer política", PAPELES de relaciones ecosociales y cambio global 129: 99-109.

Mische, A. 2003. "Cross-talk in movements: Reconceiving the culture-network link". Pp. 258-280 en Social Movements and Networks, editado por M. Diani and D. McAdam. Oxford/New York: Oxford University Press. https://doi.org/10.1093/0199251789.003.0011

Mitchell, J. C. 1969. Social Networks in Urban Settings. Manchester: Manchester University Press.

Monge, C. 2017. 15 M. Un movimiento político para democratizar la sociedad. Zaragoza: Prensas Universitarias de Zaragoza.

Navarro, V. 2014. "Por qué salió el 15-M y por qué le siguió Podemos." Diario Público, 5 de noviembre.

Porta, D. della, J. Fernandez, H. Kouki y L. Mosca. 2017. Movement Parties. Cambridge: Polity Press.

Porta, D. della. 2015. "Del 15M a Podemos: resistencia en tiempos de recesión". Entrevista con Donatella della Porta por parte de Juan Masullo y Martín Portos. ENCRUCIJADAS. Revista Crítica de Ciencias Sociales 9: 1-11.

Porta, D. della y M. Diani. 2011. Los movimientos sociales. Madrid: CIS y Editorial Complutense.

Requena, F. 1989. "El concepto de red social". Revista Española de Investigaciones Sociológicas 48: 137-152.

Rodon, T. y M. J. Hierro. 2016. "Podemos and Ciudadanos Shake up the Spanish Party System: The 2015 Local and Regional Elections". South European Society and Politics 21(3): 339-357. https://doi.org/10.1080/136087 46.2016.1151127

Rodríguez, E. 2015. "Entrevista a Emmanuel Rodríguez en el diario." El País, 10 de julio.

Rodríguez, G., J. Gil, y E. García 1996. Metodología de la investigación cualitativa. Málaga: Ediciones Aljibe.

Romanos, E. 2016. "De Tahrir a Wall Street por la Puerta del Sol: la difusión transnacional de los movimientos sociales en perspectiva comparada". Revista Española de Investigaciones Sociológicas 154: 103-118. http:// dx.doi.org/10.5477/cis/reis. 154.103 
Romanos, E. e I. Sádaba. 2016. "From the Street to Institutions through the App: Digitally Enabled Political Outcomes of the Spanish Indignados Movement". Revista Internacional de Sociología 74 (4): e048. https:// doi.org/10.3989/ris.2016.74.4.048

Simmel, G. 1986. El individuo y la libertad. Barcelona: Ediciones Península.

Snow, D. A. y P. E. Oliver. 1995. "Social Movements and Collective Behavior: Social Psychological Dimensions and Considerations". Pp.571-600 en Sociological Perspectives on Social Psychology, editado por K. S. Cook, G. A. Fine y J. S. House. Boston: Allyn and Bacon.

Snow, D. A., L. A. Zurcher y S. Ekland-Olson. 1980. "Social Networks and Social Movements: A Microstructural Approach to Differential Recruitment". American Sociological Review 45: 787-801. https://doi.org/10.2307/2094895

Soule, S. A. 2004. "Diffusion Processes Within and Across Movements". Pp. 294-310 en The Blackwell Companion to Social Movements, editado por D. A. Snow, S. A. Soule, and H. Kriesi. Blackwell Publishing, Oxford. https://doi.org/10.1002/9780470999103.ch13

Stake, R. E. 2005. Investigación con estudio de casos. Madrid: Morata.

Strang, D. y S. A. Soule 1998. "Diffusion in Organizations and Social Movements: From Hybrid Corn to Poison Pills". The Annual Review of Sociology 24: 265-90. https:// doi.org/10.1146/annurev.soc.24.1.265

Subirats, J. 2015a "Del 15-M y las gobernanzas locales al asalto de la política institucional", Ecología Política. Cuadernos de debate internacional 49: 18-27.
Subirats, J. 2015b. "Todo se mueve. Acción colectiva, acción conectiva. Movimientos, partidos e instituciones". Revista Española de Sociología 24: 123-131.

Tarrow, S. 1996. "Fishnets, internets and Catnets: Globalization and Transnational Collective Action". Working paper 1996, n 78. Centro de Estudios Avanzados en Ciencias Sociales.

Tarrow, S. 1998. El poder en movimiento. Los movimientos sociales, la acción colectiva y la Política. Madrid, Alianza Editorial.

Tilly, Ch. 1991. Grandes estructuras, procesos amplios, comparaciones enormes. Madrid: Alianza Editorial.

Toch, H. 1965. The social psychology of social movements. London: Methuen.

Touraine, A. 1990. Movimientos sociales de hoy. Barcelona: Hacer.

Wasserman, S. y K. Faust. 1994. Social Network Analysis. Cambridge: Cambridge University Press.

Weber, M. 2008. Economía y Sociedad. México: Fondo de Cultura Económica (Dos tomos).

Wellman, B. and S. D. Berkowitz 1988. Social Structures: $A$ Network Approach. Cambridge: Cambridge University Press.

White, H. C. 2009. "Redes e Historias". Revista hispana para el análisis de redes sociales 16: 1-43.

Yin, R. K. 2003. Case Study Research: Design and Methods. Thousand Oaks, London, New Delhi: Sage Publications.

JAIME MINGUIJÓN PABLO es profesor asociado de la Universidad de Zaragoza, Departamento de Psicología y Sociología, Facultad de Educación, desde el año 2011. También es director de la empresa de análisis sociológico "Milenium3, servicios de Gestión del Conocimiento, S.L.", desde enero de 2004.

DAVID PAC SALAS es profesor contratado doctor de la Universidad de Zaragoza, Departamento de Psicología y Sociología, Facultad de Economía y Empresa. En la actualidad trabaja sobre ocupaciones creativas, consumo, jóvenes y cuestiones vinculadas a la sociología política. También es decano del Colegio de Doctores y Licenciados en Ciencias Políticas y Sociología de Aragón. 